\title{
CASEREPORT
}

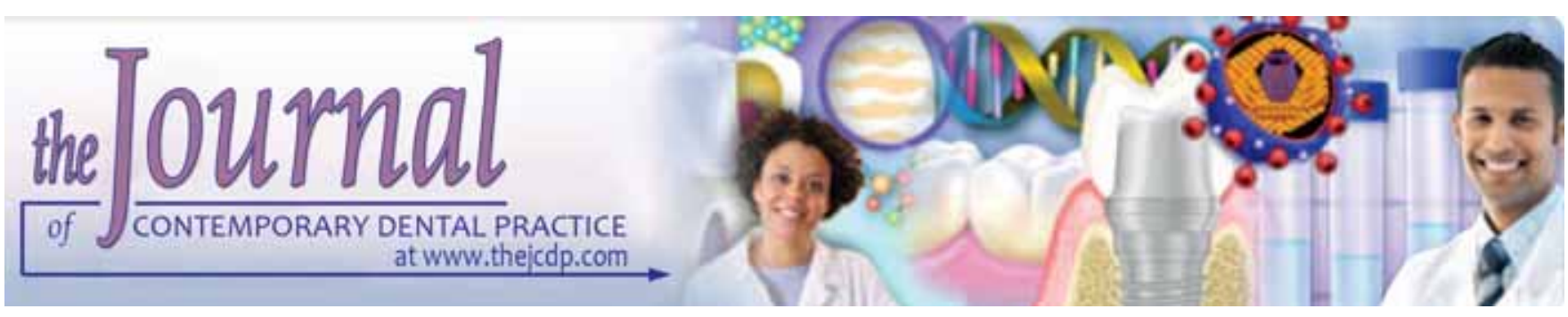

\section{Management of Severe Class II Malocclusion with Fixed Functional Appliance: Forsus}

PS Vijayalakshmi, AS Veereshi

\begin{abstract}
Background: Management of class II malocclusion in adolescent patients by growth modulation is one of the most debated topics in orthodontics. Noncompliance has been a major concern for orthodontists.
\end{abstract}

Case report: This case report describes the management of severe class II malocclusion in adolescent patient using functional appliance system-Forsus to correct class II problems, which is clipped on to bands. This appliance has several advantages, as the patient cannot remove it. It acts on the teeth and jaws for 24 hours each day, patient cooperation is not a problem, and as a result the treatment time is short. There is lot of controversy about the use of functional appliances.

Conclusion: This case report illustrates that even today, functional appliances have a significant role in the management of class II malocclusion by using growth modulation. The growth modulation minimizes the necessity of extraction of permanent teeth and probably orthognathic surgery.

Clinical significance: Functional appliances have a significant role in the management of class II malocclusion. The growth modulation minimizes the necessity of extraction of permanent teeth and probably orthognathic surgery.

Keywords: Class II malocclusion, Severe, Growth modulation and Forsus.

How to cite this article: Vijayalakshmi PS, Veereshi AS. Management of Severe Class II Malocclusion with Fixed Functional Appliance: Forsus. J Contemp Dent Pract 2011; 12(3):216-220.

\section{Source of support: Nil}

Conflict of interest: None declared

\section{INTRODUCTION}

Management of class II malocclusion by growth modulation in adolescent patients is one of the most debated topics in orthodontics. Lack of compliance in adolescent population has been a major concern of healthcare providers. Every orthodontist appreciates the seriousness of compliance.
Noncompliance has been a major concern for orthodontists for more than 40 years. ${ }^{1}$ However, predicting compliance before treatment may be difficult.

Fixed appliance for class II correction requires minimal patient cooperation and they can be grouped into three categories based upon their mode of action. ${ }^{2}$

1. Rigid fixed functional orthopedic appliance viz herbst and its modifications.

2. Fixed maxillary appliances viz pendulum appliance. Apply class I force within maxilla. The resultant orthopedic and orthodontic effects are within the maxillary arch.

3. Interarch spring force delivery system viz Jasper Jumper, Forsus.

The following case report describes the management of severe class II malocclusion in an adolescent patient using Forsus, a fixed functional appliance in single phase treatment.

A 12-year-old adolescent female patient reported with a chief complaint of protruded front teeth.

Extraoral examination in frontal view revealed increased incisal exposure and lip incompetency. Profile view showed that she had a convex profile (Figs $1 \mathrm{~A}$ to $\mathrm{C}$ ).

Intraoral findings were as follows: Severe increase in overjet of $12 \mathrm{~mm}$, overbite of $6 \mathrm{~mm}$, class II canine relation, upper dental midline shifted to right side by $1 \mathrm{~mm}$ and lower dental midline shifted to left side by $2 \mathrm{~mm}$, class II molar relation on both right and left side, curve of Spee $4 \mathrm{~mm}$ (Figs 2A to C).

Cephalometric analysis revealed class II skeletal relation with ANB of $6^{\circ}$, increased proclination of maxillary anteriors with mild vertical growth pattern.

Orthopantomogram showed a full compliment of dentition with all the third molars present.

$\mathrm{CVMI}^{3}$ assessment showed that the patient was in stage $\mathrm{V}$ (deceleration stage) of pubertal growth spurt. 


\section{Diagnosis}

Skeletal class II relation, Angle’s class II division 1 malocclusion.

\section{Treatment Objective}

Correct the skeletal class II relation to improve the convexity of the profile, occlusal objective was to achieve class I occlusion and to establish lip competency.

\section{Treatment Plan}

To change the class II relation to class I without any premolar extraction, it was decided to treat this patient with fixed functional appliance Forsus (3M Unitek) in conjunction with preadjusted edgewise appliance in single phase. A 0.022" slot MBT prescription was used.

\section{Treatment Progress}

After complete banding and bonding, leveling and aligning were done in both the upper and lower arch, until a $19 \times$ 25 " stainless steel wire could be passively placed. Individually both the arches were consolidated from molar to molar with figure of eight ligature tie and active bend back was placed in the archwire distal to the molar tube. Additional labial root torque was built into the anterior segment of lower archwire. The duration of prefunctional phase of treatment was 6 months.

Then Forsus appliance was inserted (Figs 3A to C). After two visits, a crimp was added on to the left side of Forsus for midline correction. Forsus was used for 12 months, a little longer than usual recommended duration. The occlusion was slightly overcorrected to class I, then Forsus was removed. Final finishing and detailing of occlusion were done which took about 4 months of time. After 22 months of treatment, the fixed appliance was debonded, a fixed retainer was bonded in the lower anterior region and wrap around retainer was fabricated for the upper arch.

\section{Cephalometric Analysis}

\begin{tabular}{lcc}
\hline Cephalometric reading & $\begin{array}{c}\text { Pretreatment } \\
\text { value }\end{array}$ & $\begin{array}{c}\text { Posttreatment } \\
\text { value }\end{array}$ \\
\hline SNA & $84^{\circ}$ & $83^{\circ}$ \\
SNB & $78^{\circ}$ & $79^{\circ}$ \\
ANB & $6^{\circ}$ & $4^{\circ}$ \\
Upper incisor to SN & $112^{\circ}$ & $101^{\circ}$ \\
Upper incisor to palatal plane & $120^{\circ}$ & $107^{\circ}$ \\
Lower incisor to mandibular plane & $92^{\circ}$ & $98^{\circ}$ \\
Maxillomandibular plane angle & $30^{\circ}$ & $30^{\circ}$ \\
\hline
\end{tabular}

\section{PAR (Peer Assessment Rating) Index}

\begin{tabular}{ccc}
\hline $\begin{array}{c}\text { Pretreatment PAR } \\
\text { index score }\end{array}$ & $\begin{array}{c}\text { Posttreatment PAR } \\
\text { index score }\end{array}$ & $\begin{array}{c}\text { Percentage of } \\
\text { change }\end{array}$ \\
\hline 28 & 0 & $100 \%$ \\
\hline
\end{tabular}

\section{DISCUSSION}

Management of class II malocclusion has wide spectrum of options. Since this patient was adolescent, it was decided to treat her with some form of growth modulation. The possible options are headgear to restrict the growth of maxilla, removable functional appliance and fixed functional appliance. Since, very little amount of active growth was left, we could not take a chance of patient's compliance, therefore, the option of using a headgear or removable functional appliance was ruled out. We could not use a rigid fixed functional appliance viz herbst, as we do not have the laboratory facility to fabricate herbst appliance. Hence, we decided to use flexible fixed functional appliance-Forsus.

The following changes were seen (Figs 4A to 5C) with this single phase treatment using fixed orthodontic appliance and Forsus: ANB angle was reduced from 6 to $4^{\circ}$. Upper incisor inclination with respect to palatal plane was reduced from 120 to $107^{\circ}$. Lower incisors were proclined by $6^{\circ}$. Maxillomandibular plane angle was not significantly altered. Overjet was reduced from 12 to $2 \mathrm{~mm}$. Occlusion was changed from Angle's class II division 1 to normal class I occlusion. Convexity of facial profile was reduced (Fig. 6).

PAR index ${ }^{4}$ score has changed from pretreatment value of 28 to posttreatment value zero, showing 100\% change.

Pancher $z^{5}$ has emphasized the importance of good posttreatment intercuspation for preventing the dental and skeletal relapse of class II correction. Teeth locked in stable class I intercuspation are more likely to transfer maxillary growth forces to mandible. ${ }^{5}$ This patient was in deceleration phase of growth spurt, when growth modulation treatment was done. Bacetti ${ }^{6}$ suggests that growth modulation done after the peak of growth spurt/decelerating phase of active growth spurt, results in greater skeletal contribution to molar correction.

There are lots of questions about stability of class II correction with growth modulation. ${ }^{7}$ In this patient, severe class II occlusion with $12 \mathrm{~mm}$ of overjet was very effectively treated to class I occlusion with very good posterior teeth intercuspation. Posttreatment results are absolutely stable one year after debonding (Figs 7A to C). Class II malocclusion treated with growth modulation during the pubertal growth spurt induces significant favorable dentoskeletal and occlusal changes. ${ }^{8}$

Fixed functional therapy is reported to cause a posterosuperior displacement of the maxillary dentition and pterygoid plate along with forward displacement of mandibular dentition and, thus, can contribute to the correction of class II malocclusion. ${ }^{9}$ 

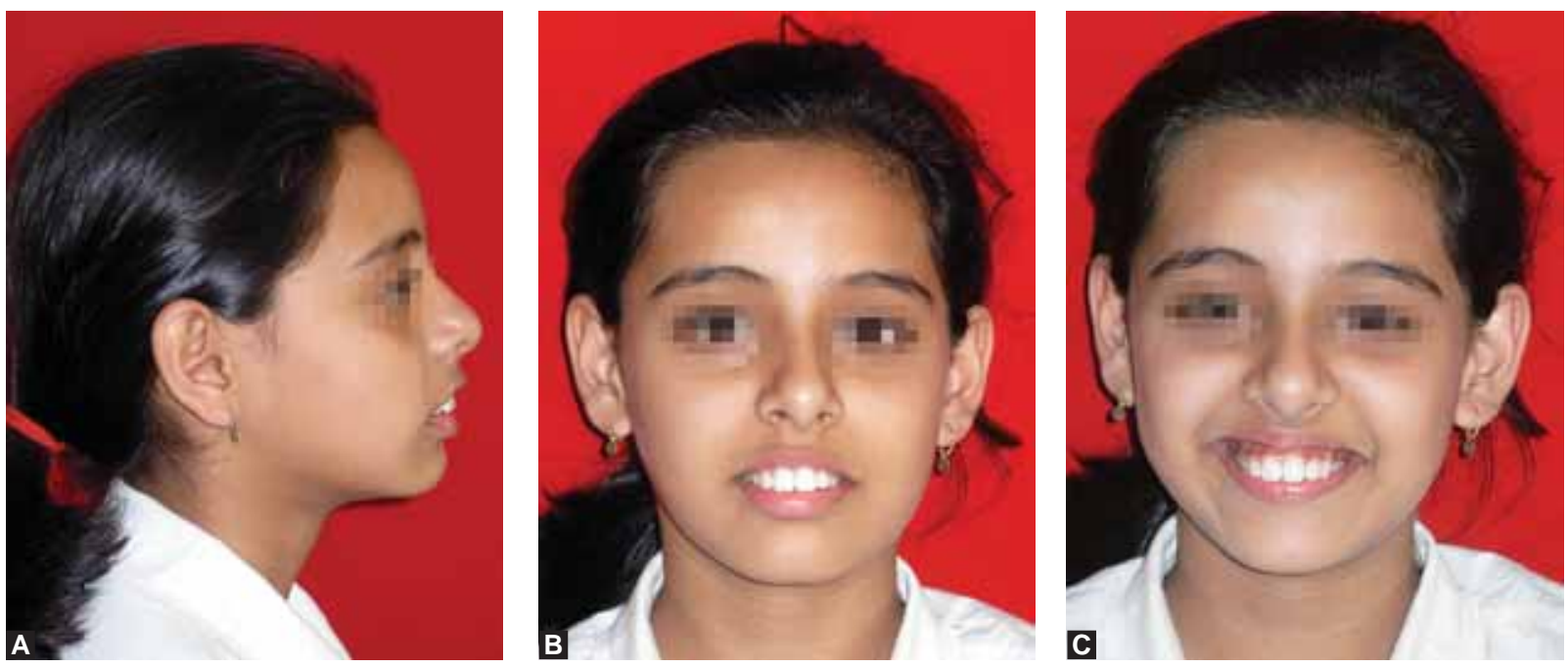

Figs 1A to C: Pretreatment extraoral photographs
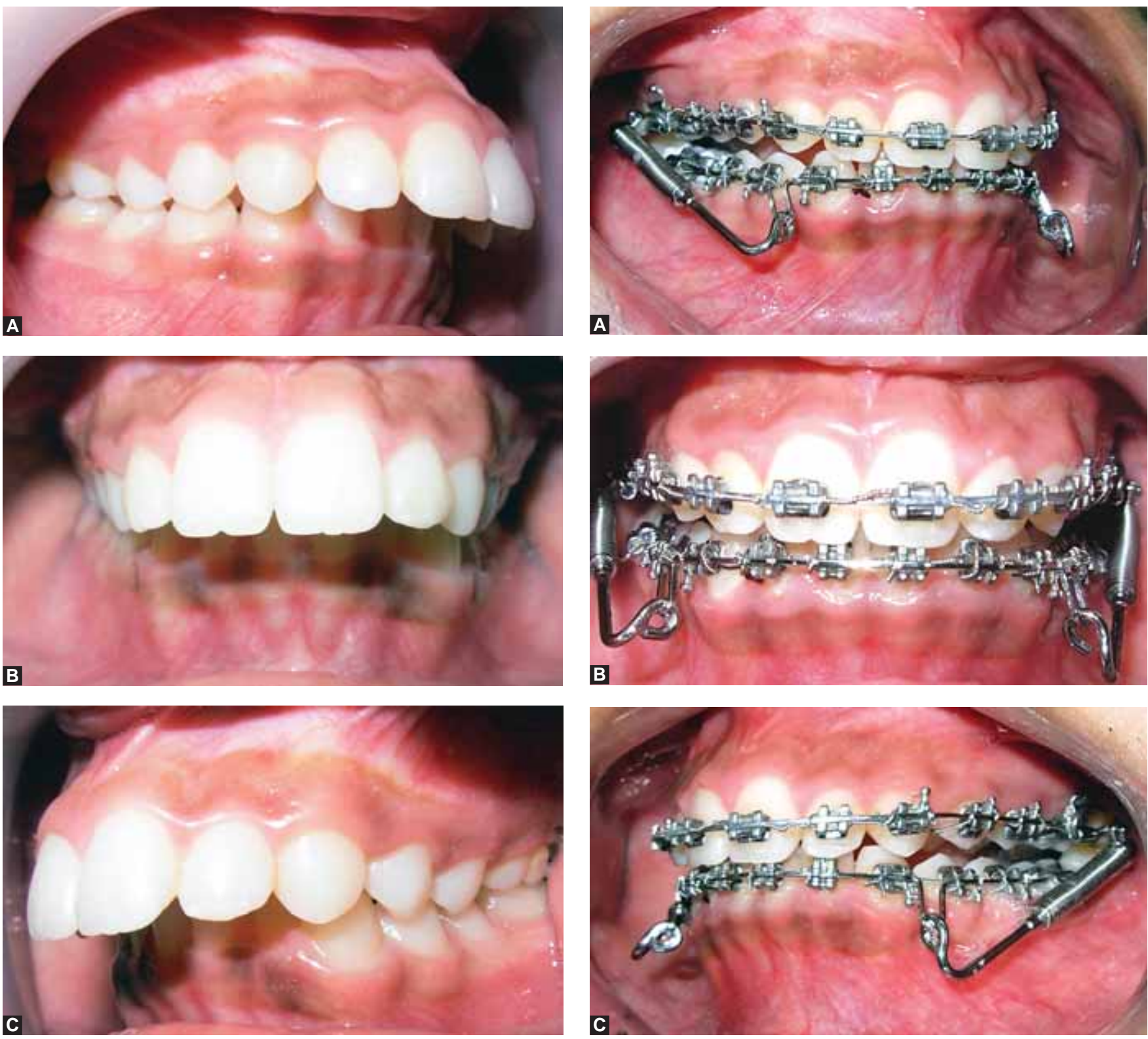

Figs 2A to C: Pretreatment intraoral photographs

Figs 3 A to C: During treatment intraoral photographs with Forsus 

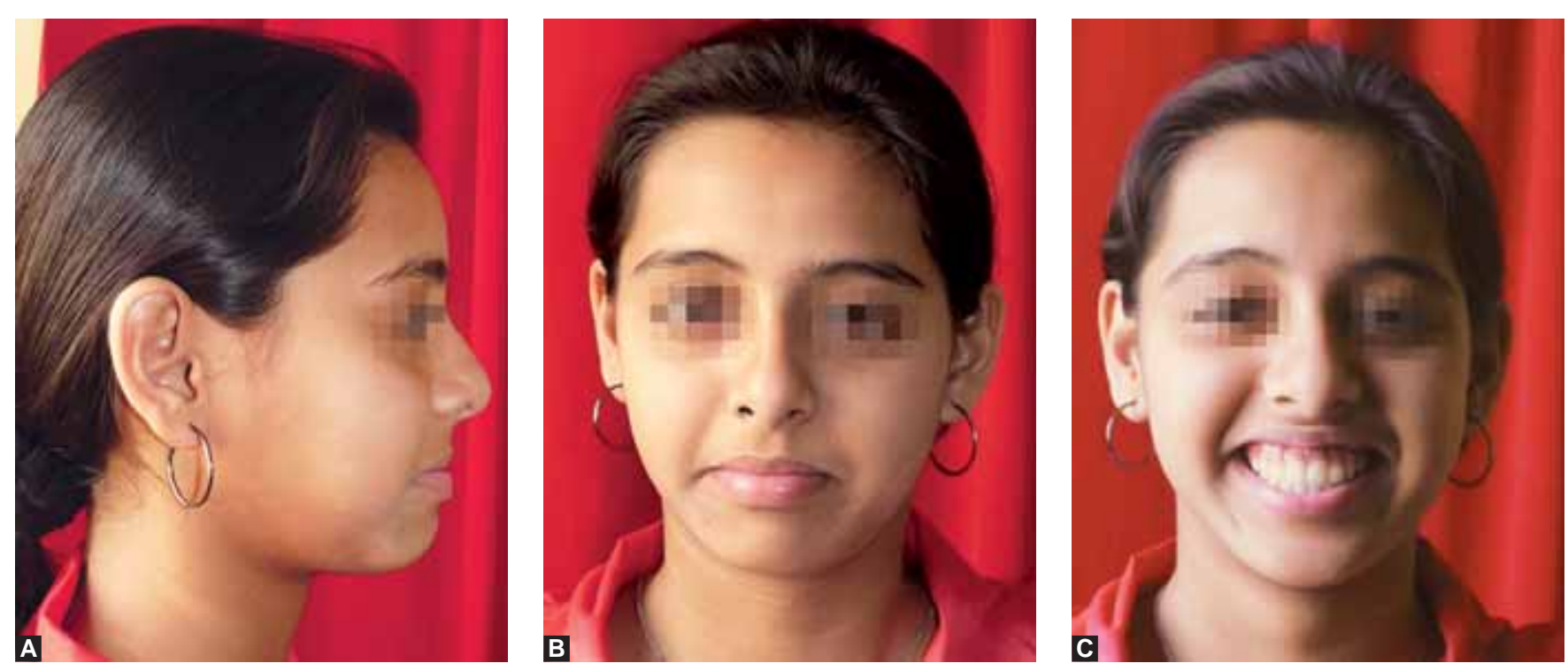

Figs 4A to C: Posttreatment extraoral photographs
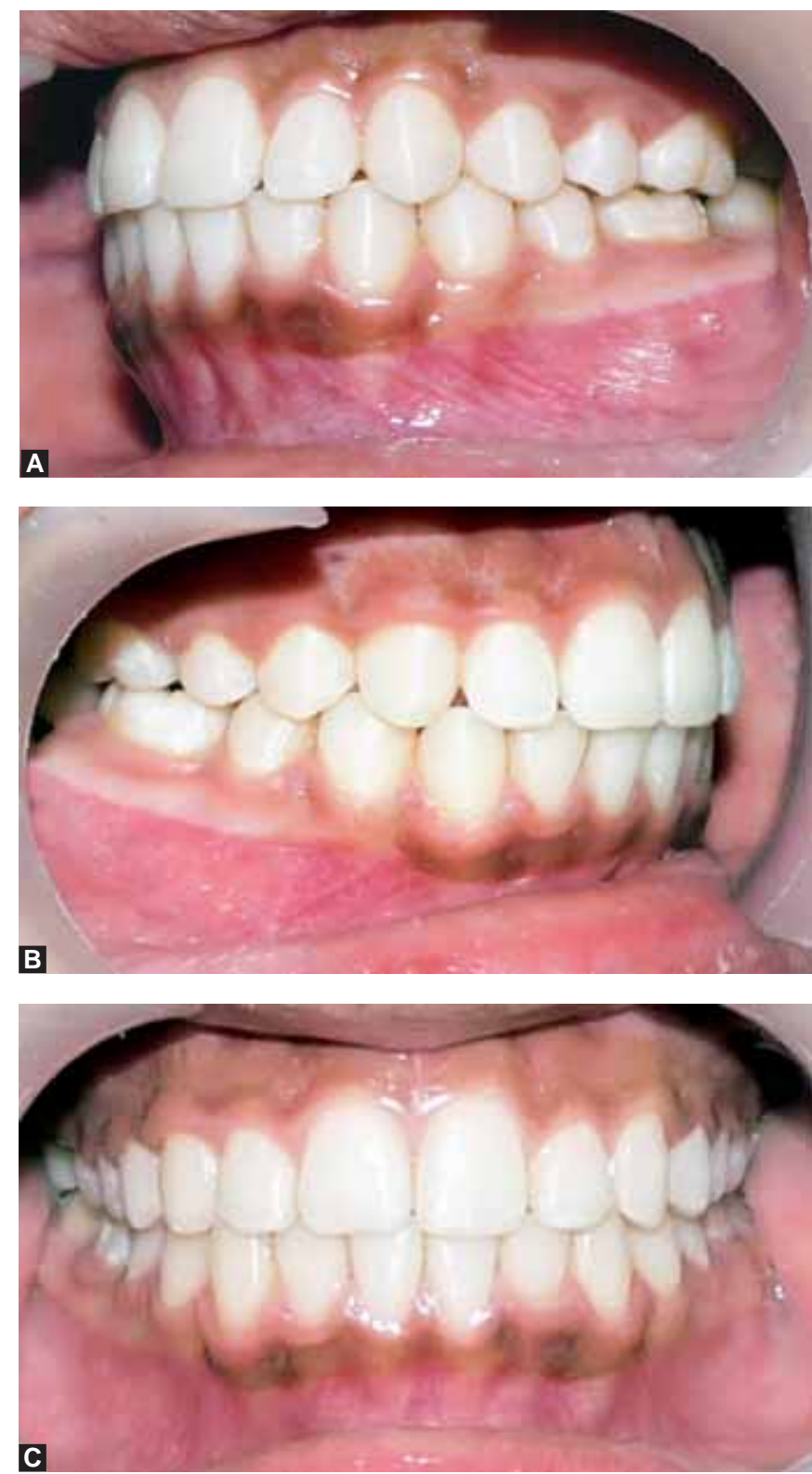

Figs 5A to C: Posttreatment intraoral photographs

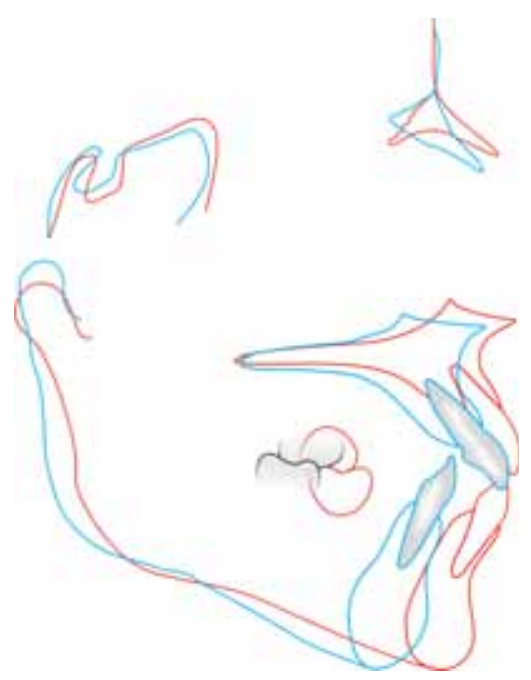

Fig. 6: Superimposition of pre- and posttreatment lateral cephalogram on Sella-Nasion plane. Pretreatment tracing is in black color ink and posttreatment tracing is in red color

The advantage of choosing growth modulation mode of treatment in this case was, it avoided the necessity of premolar extraction and an orthognathic surgery at a later stage.

The use of this viz Forsus appliance helps to integrate the functional and fixed appliance phases of therapy into single phase of treatment and minimizes the duration of treatment. Patient compliance will not be a limiting factor. Though the appliance brings about class II correction largely through dentoalveolar effects, a favorable change in the soft tissue profile with reduction in facial convexity is seen with this appliance.

\section{CONCLUSION}

In spite of all the present controversies about the growth modulation or functional appliances, even today functional appliances can be very useful tool in managing a class II malocclusion. 

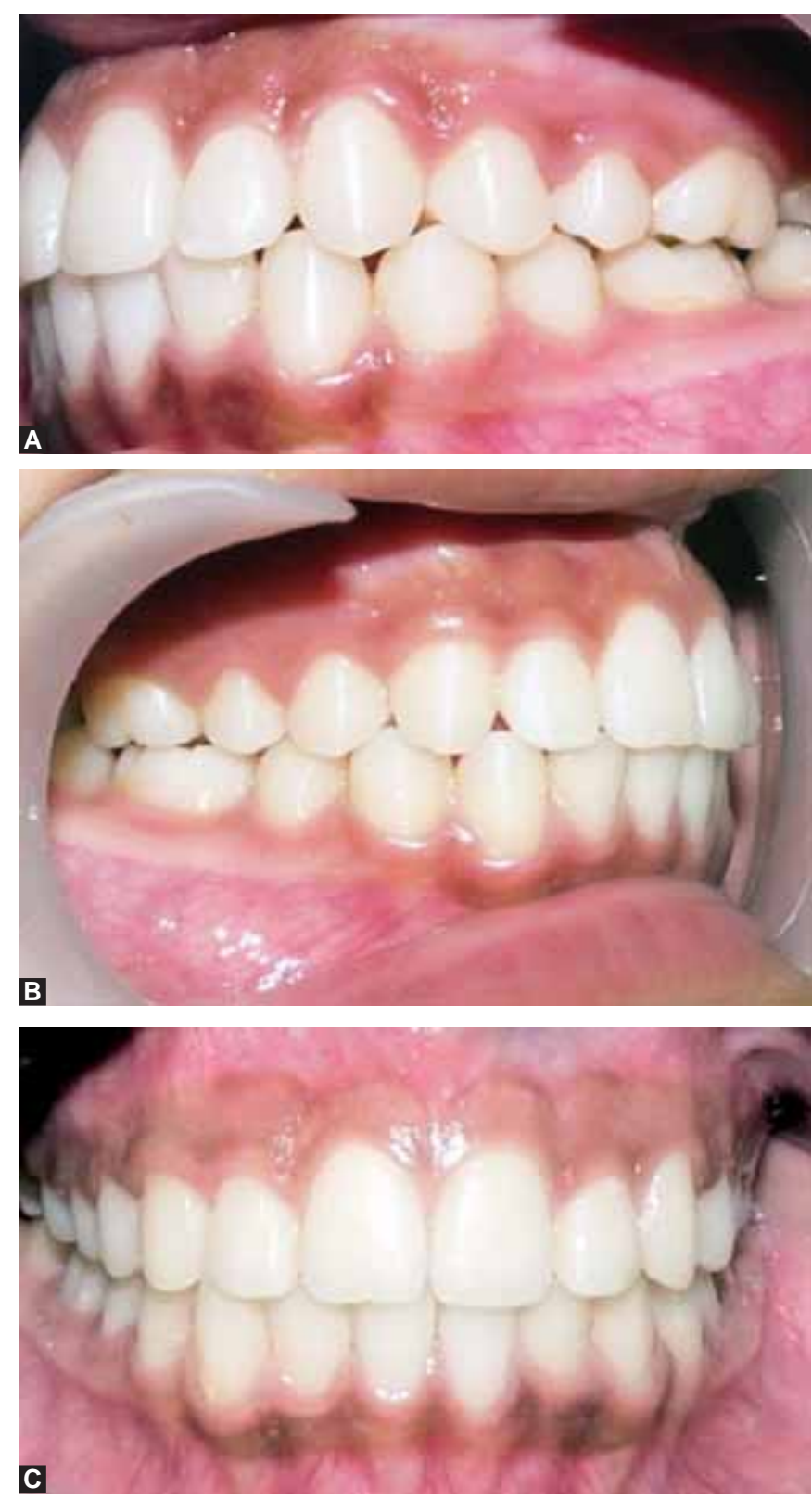

Figs 7A to C: Intraoral photographs one year after debonding

Functional appliances have a significant role in the management of class II malocclusion by using growth modulation. The growth modulation minimizes the necessity of extraction of permanent teeth and probably orthognathic surgery.

\section{REFERENCES}

1. Annemieke B, Hoogstratan J, Prahl-Andresen B. On the use of personality characteristics in predicting the compliance in orthodontic practice. Am J Orthod Dentofacial Orthop 2003;122:568.

2. Devincenzo John P. Treatment options for sagittal correction in noncomplaint patients in orthodontics: Current principles and techniques. Thomas M Graber, Robert L Vanarsdall Jr, Katherine WL, Vig Elsevier 2009:879.

3. Hassel Brent, Farman Allan G. Skeletal maturation evaluation using cervical vertebrae. Am J Orthod Dentofacial Orthop January 1995;107(1):58-66.

4. Richmond S, Shaw WC, O’Brien KD, Buchanan IB, Jones R, Stephens CD, et al. The development of the PAR index (Peer Assessment Rating): Reliability and validity. The European Journal of Orthodontics 1992;14(2):125-39.

5. Hans Pancherz. The Modern Herbst Appliance. In: Thomas M Graber, Thomas Rakosi, G Petrovic Alexandre (Eds). Dentofacial Orthopedics with Functional Appliances (2nd ed), Mosby, 1997:348.

6. Baccetti T, Franchi L, Toth LR, McNamara JA Jr. Treatment timing for twin-block therapy. Am J Orthod Dentofacial Orthop Aug 2000;118(2):159-70.

7. Nelson B, Hagg U, Hansen K, Bendeus M. A long-term followup study of class II malocclusion correction after treatment with class II elastics or fixed functional appliances. Am J Orthod Dentofacial Orthop Oct 2007;132(4):499-503.

8. Baccetti T, Franchi L, Stahl F. Comparison of two comprehensive class II treatment protocols including the bonded herbst and headgear appliances: A double-blind study of consecutively treated patients at puberty. Am J Orthod Dentofacial Orthop 2009;135(6):698-99.

9. Panigrahi Priyankar, Varadarajan Vineeth. Biomechanical effects of fixed functional appliance on craniofacial structures. Angle Orthod 2009;79:668-75.

\section{ABOUT THE AUTHORS}

\section{PS Vijayalakshmi}

\section{(Corresponding Author)}

Reader, Department of Orthodontics, DAPM RV Dental College Bengaluru, Karnataka, India, e-mail: drvijaya_ps@yahoo.com

\section{AS Veereshi}

Associate Professor, Department of Orthodontics, Rungta College of Dental Sciences and Research, Bhilai, Chhattisgarh, India 